\title{
CHANGES IN SPINAL RANGE OF MOTION AFTER 16 WEEKS TRAINING PROGRAM IN PUBERTAL CHILDREN
}

\author{
Mónika Szigethy',2, Katalin Nagyváradi1, Judit H. Ekler'1, Ferenc Ihász ${ }^{1}$ \\ ${ }^{1}$ Eötvös Lorand University Faculty of Education and Psychology, Institute of Sport Sciences, Szombathely, \\ Hungary \\ 2 Doctoral School of Education, Eötvös Loránd University, Budapest, Hungary
}

\begin{abstract}
The aim of the present research was to improve the neglect behavior of pubertal children in an intervention program. Within the framework of the program, the main function of the spinal column and the strength and extensibility of the muscles responsible for posture were investigated. The participants included in the study are 7th grade children of the Neumann János Elementary School in Szombathely, Hungary, ( $\left.n_{b}=7\right) ;(n g=10)$. The Idiag M360 Spinal Mouse was used to investigate the physiological curvatures and main function of the spinal column before and after the program. The device was used to examine the children's spines in standing, bending forward and again in a standing position after the Matthiass test was performed. Pre-intervention (1) and post-intervention (2) data showed significant decreases in all assessed characteristics and similar increases in sacrum to hip ratio (Sac/Hip) (9.83 $\pm 4.36-21.63 \pm 4.39$ ); $p<0.000$. The greatest change was found in the

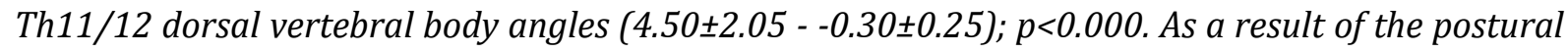
improvement program, the degree of pelvic tilt and, in parallel, the physiological curvature of lumbar lordosis was reduced to within the age-specific reference values.
\end{abstract}

Keywords: posture, Spinal Mouse, Matthiass test, posture improvement, adolescence

\section{THEORETICAL BACKGROUND}

Adolescence is a critical period of growth and maturation. Rapid growth of the support system, including the skeletal system, can lead to functional problems (STOKES, 2007). Time spent at school, which involves a largely sedentary posture, can exacerbate this already adverse phenomenon. (SMITH et al., 2011; YANG et al., 2020). The muscles of the trunk cannot keep up with this rapid growth, so their load-bearing capacity is reduced. Some of the muscles responsible for posture weaken, while others become shortened and tense. (SOMHEGYI et al., 2003). As a result of the breakdown of muscle balance, certain muscles need more effort to maintain correct posture. In other cases, the curvatures of the spine flatten, the spine becomes inflexible, muscles along its length weaken and small joints become overloaded (BAJSZ et al, 2015). Initially, there is no joint mobility limitation, the musculoskeletal apparatus is flexible, and posture can be corrected by active muscular effort.

Later, this condition becomes permanent, the curvatures of the spine deviate from the physiological position, and the loading of the spine may become asymmetric (CELENAYKAYA, 2017). Prolonged uneven loading can lead to premature cartilage wear. (BAGI et 
al., 2016). Therefore, it is important to consciously develop the muscles of the trunk, maintain and restore proper muscle balance, and establish and maintain correct posture (CARDON et al., 2007). The aim of the present study was to examine the impact of an intervention-related posture improvement program among school-age children.

\section{METHODS}

\section{PARTICIPANTS}

In total 17 children ( 7 boys; 10 girls); (age: $13.69 \pm 0.61$ ) participated in the development program, from a primary school in Western Hungary.

\section{ANTROPOMETRIC METHODS AND BODY COMPOSITION DETERMINATION}

According to the prescription of the Declaration of Helsinki the subjects were volunteer boys and girls exclusively. Beyond the kind co-operation of the children and the schoolstaff members, written consents from one of their parents were also collected before the investigation. The valid Ethical approval of this research: Ethical Committee of Eötvös Lóránd University 2020/136. The children were healthy at the time of investigation. Height was measured to the nearest $0.1 \mathrm{~cm}$ and body weight to the nearest $0.5 \mathrm{~kg}$ at the same time of day for each trial. Body composition (F\%, M\%) was measured using an OMRON BF511 (HBF-511-E) electrical impedance machine.

\section{EXAMINATION OF THE STATUS OF THE SPINE}

In our research, we used the Idiag M360 spine mouse to investigate the physiological curvatures and function of the spine. The instrument contains two roller heads that trace the line of the vertebral spinous processes of the C7-S3 vertebrae (MANNION et al., 2004; BÜYÜKTURAN et al., 2018). During scrolling, the computer collects data in two dimensions at a sampling rate of $150 \mathrm{~Hz}$ and $1.3 \mathrm{~mm}$, which are transmitted to the computer via Bluetooth (TOPALIDOUI et al., 2014; KONDOR et al., 2018).

Tests can be performed not only in static, standing position, but also in functional (forward, backward bending) and loaded position (Matthiass test) (LIVANELIOGLU et al., 2016). The software used with the device includes the parameters necessary to perform the Matthiass test. The test provides information on the strength of the pelvic, back and shoulder girdle muscles, which play an important role in posture. The test person assumes an active posture (keeping the abdominal and gluteal muscles tight, closing the shoulder blades), raises both arms to the center front and holds this position for 30 seconds (KEMPF-FISCHER, 1993). In the case of weakness of the back muscles, the curves in the sagittal plane will be pronounced, this is detected and recorded by the software (POPOVA et al., 2013).

The tests were conducted in the school's nurse's room. The room was occupied only by the testers and the children being tested. The examinee exposed his/her upper body. The investigator marked the vertebral trajectory with a marker pen and starting from the C7 cervical vertebra (vertebra prominent), the instrument was traced to the S3 sacral 
vertebra. The signals detected are transmitted by the spinal cord to the computer via Bluetooth.

The device was used to measure the children's spine, first in a standing position, then in a forward inclination position, and finally in a standing position again after the Matthiass test.

\section{IMPROVING THE CONDITION OF THE SPINE}

The students in the intervention were given a program of postural training three times a week for 4 months. The lessons consisted of 10 minutes of warm-up, 30 minutes of main part and 5 minutes of rest. During the first two weeks, the children learned how to perform correctly the exercises used in the program and the criteria for setting the correct posture. The amount and intensity of the workload was increased from the third week onwards, following the principle of gradualness. The complexity of some exercises was increased, while in others the number of repetitions was increased. The following exercises were used on each occasion:

1. Mobilization of the spinal column in sagittal plane, stretching the muscles of the abdomen, back and neck:

Description: from a starting position of kneeling support, arch back, tilt pelvis back, retract abdomen, slowly bend head forward (Picture 1a), hold end position for a few seconds. Afterwards, during squatting, raise head, tilt pelvis forward, squat lumbar spine (Picture 1b), and hold end position for a few seconds.

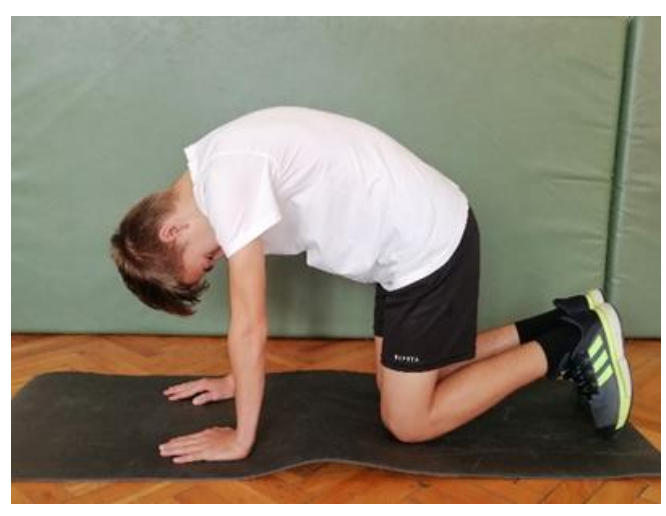

Picture: $1 \mathrm{a}$

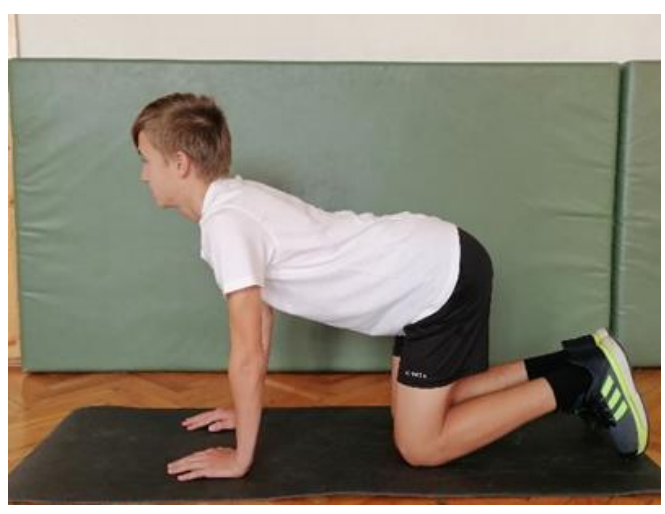

$1 b$

2. Mobilization of the spine in the horizontal plane

Description: starting position: lying supine position with footrest with arms at the sides. Turn torso, arms and head to the right, lower legs to the ground on the left (Picture 2a). 
Hold this position for 6-8 seconds, then perform the exercise on the opposite side (Picture $2 \mathrm{~b})$.

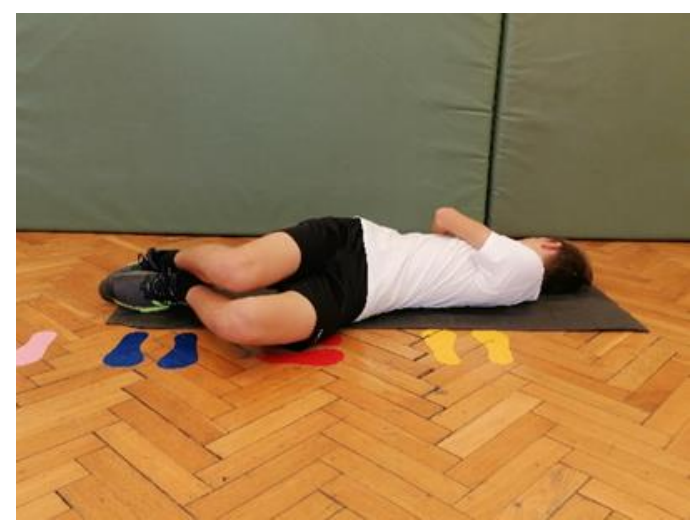

Picture: $2 \mathrm{a}$

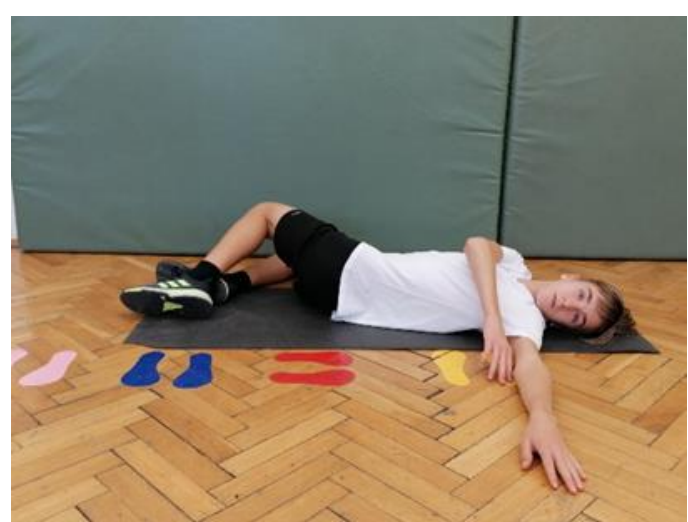

$2 b$

3. Strengthening the superficial back muscle group

Description: starting position: prone, forehead support on the ground, arms to the ears. Slowly raise arms above ear line (Picture 3a), elbow pull to shoulder line (Picture 3b), extend arms into high hold (Picture 3a), then return to floor.

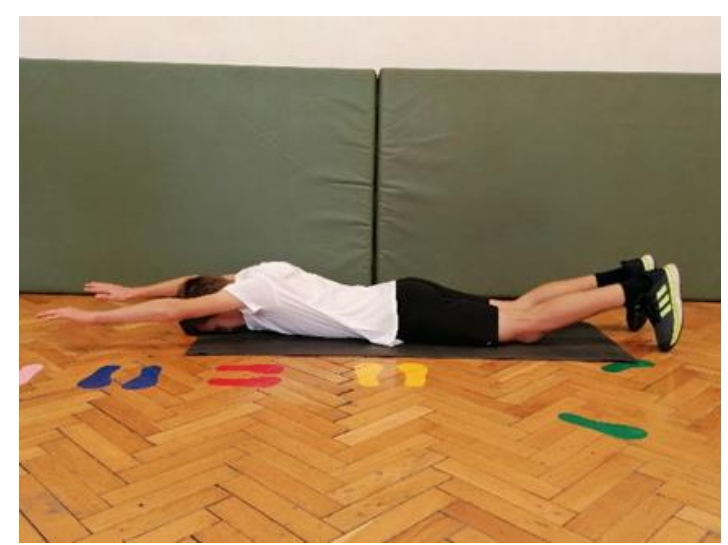

Picture: $3 a$

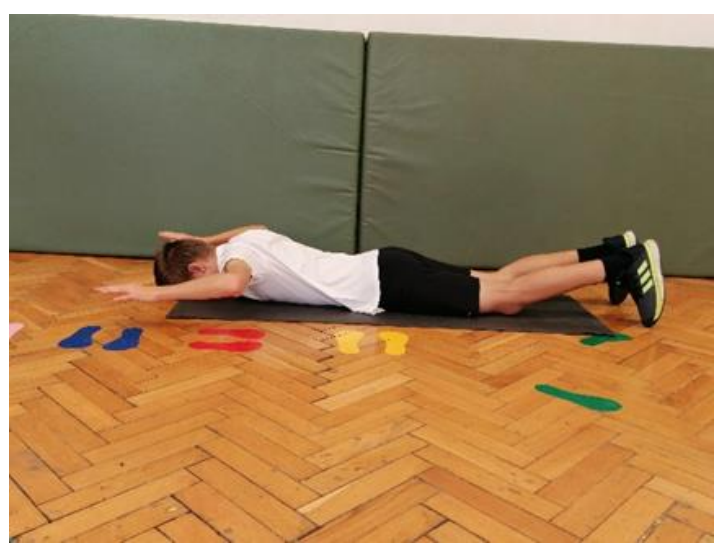

$3 b$

4. Pelvic stabilization and abdominal strengthening exercise

Description: Starting position: lying on your back, arms in the middle of the chest, thighs vertical, lower leg flexed at 90 degrees, parallel to the floor (Picture 4a). Tilt pelvis back so that the waist remains on the ground. From here, perform slow arm and leg extensions (Picture 4b). 


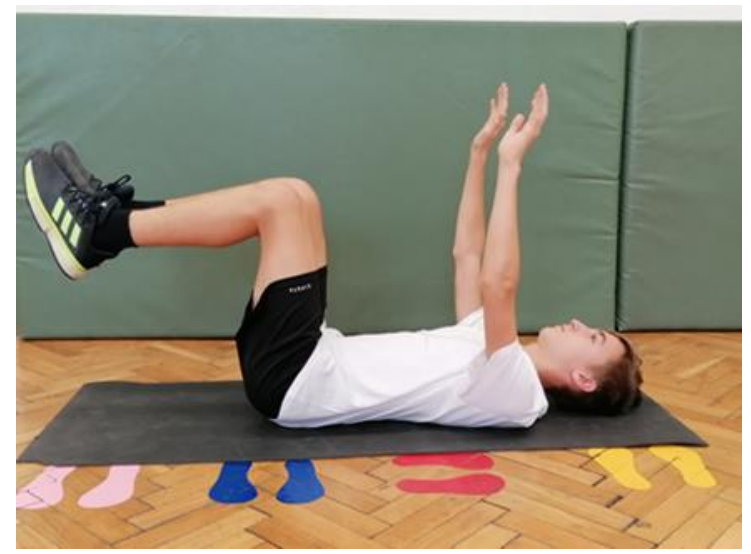

Picture: $4 \mathrm{a}$

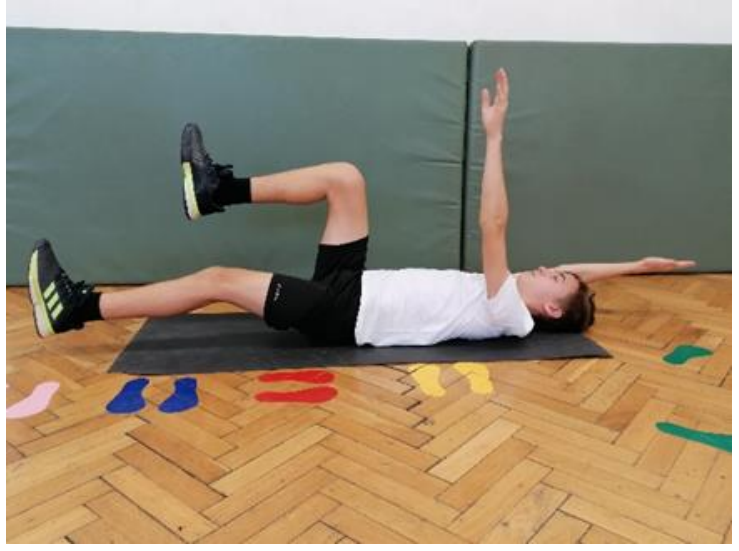

$4 \mathrm{~b}$

5. Compound strengthening exercise: strengthening of superficial and deep back muscles, thigh, and gluteus muscles

Description: Starting position: shoulder-width apart, feet pointing forward. Bend hips and knees, tilt pelvis back, tilt torso slightly, lift arm into a high position (Picture 5). Hold end position for a few seconds, then rise to starting position.

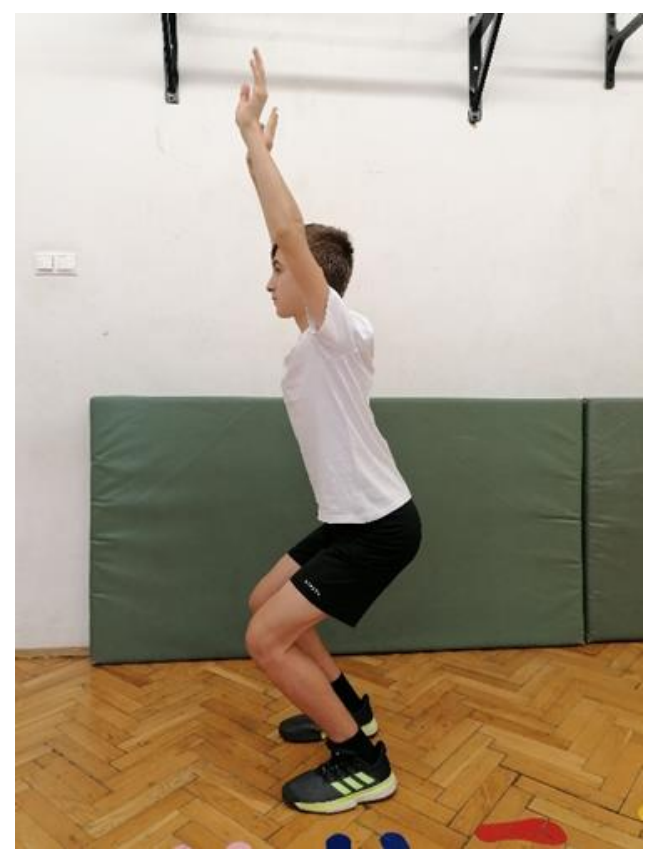

Picture: 5

\section{STATISTICAL ANALYSIS}

The data recorded during the tests were carried out using the Statistica for Windows 13.2 software package. Differences in anthropometric (BH, BW) and body composition (F\%, $\mathrm{M} \%$ ) means between sex and study were examined using one-way ANOVA. Changes in means of spine regions (means of three measurements) were analyzed by repeated measure ANOVA, Post Hoc, Tuckey's method with random error at the $\mathrm{p}<0.05$ level. 


\title{
RESULTS
}

Table 1 listed the means (and standard deviations) for body height (BH), body weight (BW) and body composition (F\%, M\%) measure before and after intervention both genders. As for the changes in anthropometric and body composition averages, we decided to compare the results of two measurements - the first and the last - because the intermediate measurement was close in time, and this is too short time to show the changes. The ANOVA indicated significant differences were found between the sexes in all the characteristics tested, except for body height, in the first measurement. And for the second measurement, differences were real for all other characteristics except body weight averages. In terms of body composition, the children in the intervention $[\mathrm{I}(2) \mathrm{F} \%(\mathrm{~B}-\mathrm{G})=19.70 \pm 8.78-30.11 \pm 8.06]$ were slightly overweight, regardless of sex.

Table 1: Comparison of anthropometric and body composition characteristics of the participating children in the program

$\begin{array}{cccccc} & \text { I (1) } & & & \\ & \begin{array}{c}(n=7) \\ \text { mean (Boys) }\end{array} & \text { sd } & \begin{array}{c}(n=10) \\ \text { mean (Girls) }\end{array} & \text { sd } & \text { P } \\ \text { BH (cm) } & 159,71 & 8,75 & 159,20 & 4,49 & \text { NS } \\ \text { BW (kg) } & 56,41 & 21,90 & 65,60 & 18,27 & \mathrm{~B}<\mathrm{G} \\ \mathbf{F \%} & 21,34 & 10,26 & 31,26 & 7,93 & \mathrm{~B}<\mathrm{G} \\ \mathbf{\text { M\% }} & 35,87 & 2,64 & 31,23 & 2,75 & \mathrm{~B}>\mathrm{G} \\ & (n=7) & \mathbf{I}(\mathbf{2}) & (n=10) & & \\ \text { BH (cm) } & 164,92 & 9,96 & 160,40 & 5,05 & \mathrm{~B}>\mathrm{G} \\ \mathbf{B W}(\mathbf{k g}) & 62,57 & 21,91 & 66,50 & 18,91 & \mathrm{NS} \\ \mathbf{F \%} & 19,70 & 8,78 & 30,11 & 8,06 & \mathrm{~B}<\mathrm{G} \\ \mathbf{M \%} & 37,36 & 3,10 & 31,85 & 3,00 & \mathrm{~B}>\mathrm{G}\end{array}$

\begin{abstract}
Abbreviations: $\mathrm{BH}=$ body height $(\mathrm{cm}), \mathrm{BW}=$ body weight $(\mathrm{kg}), \mathrm{F} \%=$ body fat percentage, $\mathrm{M} \%=$ body muscle percentage, I(1)=first measurement before intervention, $I(2)=$ second measurement after intervention
\end{abstract}

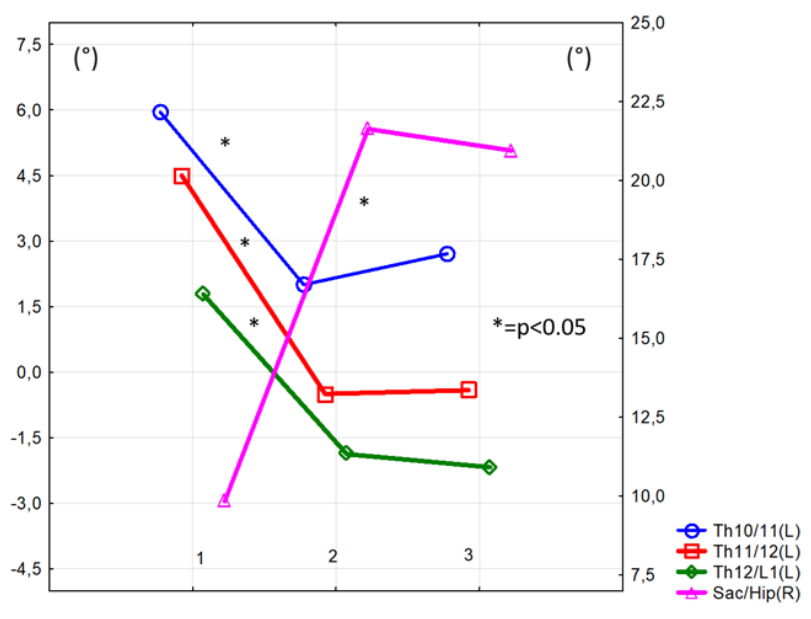

Figure 1: Changes in angular position of spinal regions as a result of intervention 
Abbreviations: Th10/11=dorsal spine vertebrae, Th11/12= dorsal spine vertebrae, Th12/L1=dorsal and lumbar spine vertebrae, Sac/Hip=sacral to hip ratio.

Figure 1 shows the changes in the different points of the spinal column before, during and after the intervention. The $y$-axis on the right shows the sacral angle (Sac/Hip) (this represents the pelvic position) and the y-axis on the left shows the lower back (Th10/11; Th11/12) and the last back and first lumbar (Th12/L1) regions of the spinal column. Preintervention (1) and post-intervention (2) data showed significant decreases in all assessed characteristics and similar increases in sacrum to hip ratio (Sac/Hip) (9.83 \pm 4.36 - 21.63 \pm 4.39 ); $\mathrm{p}<0.000$. The greatest change was found in the Th11/12 dorsal vertebral body angles ( $4.50 \pm 2.05-0.30 \pm 0.25) ; \mathrm{p}<0.000$. The presence training was blocked because of the COVID-19 lockdown between the second and the third test, so the results of the third measurement did not change.

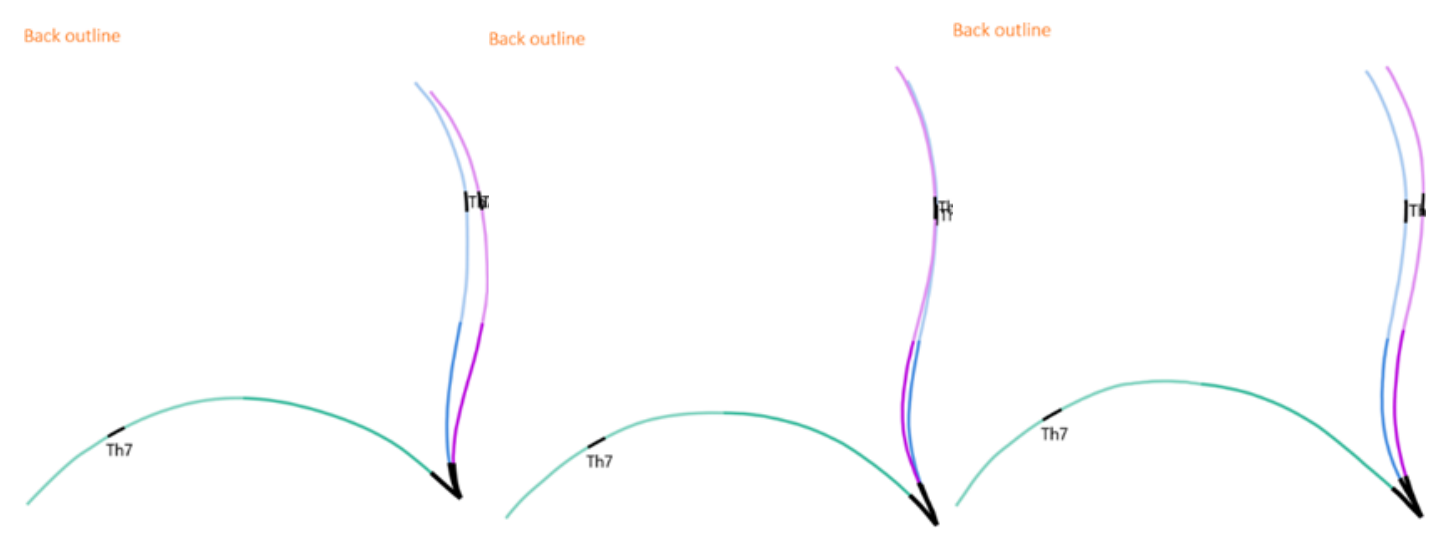

Legend: 1. measurement: 03. 10. 2020. 2. measurement: 02.26. 2021. 3. measurement: 2021.05.20.

The figures above show the results of one child, done at three different times. The blue line shows the spinal column in the standing position. The green line shows the pattern of the spinal column during forward inclination and the purple line shows the condition after the Matthias test.

\section{DISCUSSION}

Physical activity gradually decreases in pubertal subjects, and a sedentary lifestyle is a risk factor for a decline in their state of health. It is important to increase methodological indications for exercise programs for schoolchildren. We used an innovative training protocol, including several combined exercises for core stability and spine flexibility.

Regarding the motivational aspect, our training protocol appeared to be particularly appropriate to encourage subjects to participate and adhere to the training program. Participation in an exercise-training program is very difficult in all age groups, but particularly in pubertal kid's, adherence to a physical activity period is more challenging (DISHMAN- BUCKWORTH, 1996). 
The difference between the measured data (Th11-Th12) before and after the intervention was significant. The kyphotic curvature decreased, flattened. This indicates that the muscles were strengthened, as there was not as much elongation in the back muscles after the exercise test as before the intervention.

For the second and third measurements, a minimal relapse was observed for the same spinal section. In the Th11 / 12 and Th12 / L1 segments, the first two measurements showed significant improvement in both regions. Behind the favorable change, a similar physiological process can be observed as in the previous segments. The quotient of the sacrum and the hip (Sac / Hip), which is the angle between the sacrum and the vertical plane, represents the position of the pelvis in space. The tilt of the sacrum and with it the pelvis determine the posture. In the sample we examined, the low values measured during the first study were in many cases associated with the absence or very mild presence of lumbar lordosis (straightened lumbar spine). Because of the posture improvement program, the degree of pelvic tilt and, in parallel, the physiological curvature of lumbar lordosis was reduced to age-specific reference values. This is an important change because when the lumbar concavity is smoothed, the upper part of the abdominal muscles shrinks, the deep back muscles become inactive, and this part of the spine loses its elasticity.

In one specific case (Legend 1 ) the blue and purple lines are visibly separated, suggesting that the child's back muscles are weak, as the purple curve after the test is much more pronounced. The physiological curvatures of the spine are not adequate either, the lordotic curvature is almost absent in the lumbar region. After the intervention (Legend 2 ), the figure taken during measurement 2 shows that the two curves run almost on top of each other, suggesting that we were able to significantly improve the holding weakness, so the images after the numbers also confirmed the effectiveness of the program. There was also a change during physiological curves; where the curvature of lumbar lordosis was formed. During the third measurement (Legend 3), which occurred after the first wave of the pandemic: the course of physiological curves was maintained, but the effect of the posture improvement achieved during the intervention was reduced, ie a small degree of postural weakness was restored in the case of the examined student.

\section{CONCLUSION}

In conclusion, our findings indicate that the flexibility training protocol performed for 16 weeks could improve the status of the spinal in pubertal children. These data might be suitable for increasing knowledge about the methodology of spinal prevention gymnastics. In particular, this study showed that a specific workload pattern (set, repetitions, and type of exercise) could increase the status spinal in pubertal children. 


\section{REFERENCES}

Bagi, N., Sápi, O. \& Fehérné Kiss, A. (2016). A funkcionális gerinctréning szerepe a hanyag tartás kezelésében. Fizioterápia, 25(4), 22-26.

Bajsz, V., Császárné Gombos, G., Sió, E. \& Tóthné Steinhausz, V. (2015). Mozgásszervi betegségek megelőzése, Pécsi Tudományegyetem, Pécs.

Büyükturan, Ö., Büyükturan, B., Yetiș, M. \& Yetiş A. (2018). Assessment of thoracic kyphosis and lumbar lordosis on skin-surface in older adults: Spinal Mouse validity and reliability. Dicle Medical Journal, 45(2), 121-127. DOI: 10.5798/dicletip.410864.

Cardon, G.M., de Clercq, D.L., Geldhof, E. J., Verstraete, S.\& de Bourdeaudhuij, I.M. (2007). Back education in elementary schoolchildren: the effects of adding a physical activity promotion program to a back care program. European Spine Journal, 16. 125-133. DOI: 10.1007/s00586-006-0095-y.

Celenay S.T \& Kaya D.Ö. (2017). An 8-week thoracic spine stabilization exercise program improves postural back pain, spine alignment, postural sway, and core endurance in university students: a randomized controlled study. Turkish Journal of Medical Sciences, 47. 504-513. doi:10.3906/sag-1511-155.

Dishman RK, Buckworth J. (1996) Increasing physical activity: a quantitative synthesis. Med Sci Sports Exerc. 28(6):706-719.

Kempf, H. D. \& Fischer, J. (1993). „Rückenschule für Kinder”. Deutschland

Kondor, J., Széll, A. \& Tihanyi, J. (2018). Az aktív elongációs technika hatása a gerincoszlop morfológiai jellemzőire. Biomechanica Hungarica, 11(2), 31-41. DOI: $10.17489 / 2018 / 2 / 05$. 
Livanelioglu, A., Kaya, F., Nabiyev, V., Demirkiran,G. \& Firat, T. (2016). The validity and reliability of "Spinal Mouse" assessment of spinal curvatures in the frontal plane in pediatric adolescent idiopathic thoraco-lumbar curves. European Spine Journal, 25(2), 476-482. doi: 10.1007 / s00586-015-3945-7.

Mannion, A. F., Knecht K., Balaban, G.,Dvorak, J. \& Grob, D.(2004). A new skin-surface device for measuring the curvature and global and segmental ranges of motion of the spine: Reliability of measurements and comparison with data reviewed from the literature. European Spine Journal, 13(2), 122-136. doi: 10.1007 / s00586-003-0618-8.

Popova Ramova E., Poposka A. \& Ramov L. (2013). School screening for spine deformity with clinical test and spine mouse device. Jokull, 63(7), 97-105.

Smith, A. J., O’Sullivan, P. B., Beales, D. J., Klerk, N. \& Straker, L. M. (2011). Trajectories of childhood body mass index are associated with adolescent sagittal standing posture. Int. J. Pediatr. Obes., 6(2), 97-106. DOI: 10.3109/17477166.2010.530664

Somhegyi, A., Gardi, Zs., Feszthammer, A-né, Darabosné Tim, I. \& Tóthné, S. V. (2003). Tartáskorrekció. A biomechanikailag helyes testtartás kialakításához szükséges izomerō és izomnyújthatóság ellenőrzését és fejlesztését elősegítő gyakorlatok., Magyar Gerincgyógyászati Társaság, Budapest.

Stokes, I. A. F. (2007). Analysis and simulation of progressive adolescent scoliosis by biomechanical growth modulation. European Spine Journal, 16(10), 1621-1628. doi: 10.1007 / s00586-007-0442-7.

Topalidoui, A., Tzagarakisi, G., Souvatzis, X. \& Katonisi, P. (2014). Evaluation of the reliability of a new non-invasive method for assessing the functionality and mobility of the spine. Acta of Bioengineering and Biomechanics, 16(1), 117-124., DOI: $10.5277 / a b b 140114$. 
Vol 4, No 2 (2021): Stadium -Hungarian Journal of Sport Sciences

https://doi.org/10.36439/shjs/2021/2/10560

Yang, L., Lu, X., Yan, B. \& Huang, Y. (2020). Prevalence of Incorrect Posture among Children and Adolescents: Finding from a Large Population-Based Study in China. iScience, 23(5), doi: 10.1016 / j. isci.2020.101043 